\title{
Study on Cumulative Damage Law of Stainless Steel-Reinforced Concrete Columns under Step Impact Loading
}

\author{
Bo Wu, ${ }^{1,2,3}$ Shixiang $X u\left(\mathbb{D},{ }^{1,2,3}\right.$ and Guoxue Zhang $\mathbb{D}^{4}$ \\ ${ }^{1}$ College of Civil Engineering and Architecture, Guangxi University, 100 University Road, Nanning, Guangxi 530004, China \\ ${ }^{2}$ The Key Laboratory of Disaster Prevention and Engineering Safety of Guangxi, Nanning 530004, China \\ ${ }^{3}$ The Key Laboratory of Disaster Prevention and Structural Safety of Ministry of Education, Guangxi University, \\ Nanning 530004, China \\ ${ }^{4}$ School of Transportation and Civil Engineering \& Architecture, Foshan University, Foshan 528000, China
}

Correspondence should be addressed to Shixiang Xu; 603559081@qq.com

Received 1 July 2019; Accepted 27 August 2019; Published 10 October 2019

Guest Editor: Alexander Balitskii

Copyright (C) 2019 Bo Wu et al. This is an open access article distributed under the Creative Commons Attribution License, which permits unrestricted use, distribution, and reproduction in any medium, provided the original work is properly cited.

In this study, an ultrahigh drop hammer impact test system was adopted for multiple horizontal impact tests on stainless steelreinforced concrete columns and ordinary-reinforced concrete columns with the same longitudinal reinforcement diameter. The damage performance after impact was studied, and the finite element model was established. The test measured the impact force, displacement, cracking of the specimen during the impact, and the concrete damage near the bottom of the specimen. The test results showed that the failure mode of the stainless steel-reinforced concrete specimen under multiple impacts was the same as that of the ordinary reinforced concrete specimen. Under the same impact conditions, the maximum impact force, the maximum displacement, and the damage degree of stainless steel-reinforced concrete column specimen were lower than those of the ordinary reinforced concrete specimen.

\section{Introduction}

Compared with ordinary steel bars, stainless steel bars have better advantages in strength, ductility, corrosion resistance, and maintenance cost. A large number of stainless steel bars were used in the Hong Kong-Zhuhai-Macao Bridge that has been opened to traffic. It is a development trend to replace ordinary reinforced concrete structures with stainless steel bars. Reinforced concrete columns are one of the most important components in bridges and building structures. Damage or damage under impact loads may cause partial or total collapse of the structure, causing catastrophic consequences.

Tian and Zhu [1] established a damage assessment method for members based on the vertical residual load capacity of reinforced concrete columns after impact, which was used to determine the damage degree of reinforced concrete columns under impact loads and analysis of the protective measures for column protection. Cheng et al. [2] conducted a numerical study on the dynamic response of reinforced concrete columns under impact and analyzed the effects of collision velocity, mass, collision shape, reinforcement ratio, and concrete strength grade on deformation and impact force. Loedolff [3] conducted a horizontal impact test on the impact resistance of reinforced concrete cantilever columns. Liu et al. [4] studied the failure mode and transformation mechanism of axially compressed reinforced concrete columns under lateral impact loads using the finite element method. Demartino et al. [5] and Cai et al. [6] carried out an experimental study on the impact resistance of scaled reinforced concrete bridge piers. Zhou et al. [7] established a reliability analysis method for shear performance of reinforced concrete piers under falling rock impact load and discussed the influence of different parameters on the shear performance of columns. Wang et al. [8] studied the dynamic response of simply supported RC columns with axial compression under lateral impact loads and analyzed the effect of loading rate, longitudinal 
reinforcement ratio, and stirrup reinforcement ratio on the failure mode and carrying capacity. Zhao and Qian [9] used numerical simulation to study the performance of reinforced concrete piers under lateral impact loads, to analyze the dynamic response and impact resistance of the piers under lateral impact loads, and to discuss the effects of different collision parameters on the failure mode and the damage mechanism of reinforced concrete piers. Zhang et al. conducted an experimental study on the impact resistance of stainless steel-reinforced concrete $[10,11]$ and used ultrasonic waves to simple analyze the damage of the pier specimens after impact [12].

In the present study, based on the application of stainless steel-reinforced concrete piers of the Hong Kong-ZhuhaiMacao Bridge, an ultrahigh multifunctional drop hammer impact test system was applied for the experimental research of the cumulative damage of stainless steel-reinforced concrete columns under the horizontal impact loads. Also, the ordinary reinforced concrete specimens with the same longitudinal reinforcement diameter were compared and analyzed. The results have reference significance for the impact analysis and design of stainless steel-reinforced concrete columns.

\section{Experimental Programme}

2.1. Design of the Specimen. In this experimental study, two cylindrical column specimens were designed, one of which was a stainless steel-reinforced concrete column numbered R1 and the other which was an ordinary reinforced concrete column numbered R2. The specimens were made of C40 concrete, with column section diameters of $340 \mathrm{~mm}$ and a column height of $2,200 \mathrm{~mm}$. The experimental stainless steel bars were an S2304 duplex stainless steel reinforcement, and the longitudinal reinforcement used in the ordinary RC bridge pier specimen was HRB335 reinforcement. The design parameters of the test specimens are shown in Table 1, the properties of the steel materials are shown in Table 2, and the detail drawing of reinforced concrete is shown in Figure 1.

2.2. Test Device. This study's experiment was conducted using an ultrahigh drop hammer impact test system. By adjusting the vertical height of the drop hammer, the free fall of the drop hammer could be used as the traction of a car with different motion rate levels. The mass of the drop hammer was $196 \mathrm{~kg}$, the impacting car body was $1.2 \mathrm{t}$, the bottom of the column test specimen was fixed with highstrength bolts, and the vertical shaft pressure of $250 \mathrm{kN}$ was applied on the top of the test specimen, as shown in Figure 2.

During the test, the impact force, displacement, and crack development of the test specimens were collected and recorded. Four displacement meters were arranged at the back of the specimen from top to bottom at $100 \mathrm{~mm}$, $800 \mathrm{~mm}, 1,500 \mathrm{~mm}$, and 2,100 mm, as shown in Figure 3, and numbered as $\# 1, \# 2, \# 3$, and $\# 4$. In order to obtain the damage degrees of the specimens, a ZBL-U520 nonmetal ultrasonic detector was used to test the specimens and the main detection parts were the bottoms of the specimens.
2.3. Model Test. The drop hammer was lifted to a certain height and then released, in order to track the car's impact on the specimen. The impact velocity was obtained using a laser velocity measuring system set at the end of the track, and the impact force was measured using a pressure sensor set at the impacting car's head. In order to record the crack development during the impact of the specimen, the crack width of the specimen was measured by a crack width measuring instrument. The data acquisition system uses the high performance dynamic signal analysis system DH8302 of Jiangsu Donghua Test Technology Co., Ltd.

\section{Results and Discussion}

3.1. Time-History Curve for the Impact Force. Figure 4 shows the time-history curve of the impact force of the stainless steel-reinforced concrete specimens with the drop hammers lifted to $2 \mathrm{~m}, 4 \mathrm{~m}, 6 \mathrm{~m}$, and $8 \mathrm{~m}$, respectively. As the impact energy continues to increase, the maximum impact force also increases. The maximum impact force under the impact of $2 \mathrm{~m}, 4 \mathrm{~m}, 6 \mathrm{~m}$, and $8 \mathrm{~m}$ was $130264 \mathrm{~N}, 196819 \mathrm{~N}, 236707 \mathrm{~N}$, and $269763 \mathrm{~N}$, respectively. It can be seen from Figure 5 that under the same impact conditions, the maximum impact force of ordinary reinforced concrete specimens was $142136 \mathrm{~N}, 215166 \mathrm{~N}, 285176 \mathrm{~N}$, and $317289 \mathrm{~N}$, respectively. By comparing the stainless steel-reinforced concrete specimens with ordinary reinforced concrete specimens under the same impact conditions, it was found that the impact force peak of stainless steel-reinforced concrete specimens under the same impact condition was significantly lower than that of ordinary reinforced concrete column specimens, and the shock during the impact of the ordinary reinforced concrete specimen was more complicated than the stainless steel-reinforced concrete specimen. This was mainly due to some characteristics of the stainless steel reinforcement itself.

\subsection{Research on Damage Degree Based on the Damage Factor.} In order to obtain an accurate description of the damage degree of the specimens, the damage degree of the specimens are quantitatively described based on the ultrasonic wave velocity, and the damage factor $D$ is introduced.

The damage factor is defined as follows:

$$
D=1-\frac{v^{2}}{v_{0}^{2}},
$$

where $v$ is the wave velocity after damage and $v_{0}$ is the initial wave velocity.

From the change of the ultrasonic wave velocity before and after the impact, the damage factor of each specimen can be obtained according to the aforementioned formula. The change of the damage factor after each impact is shown in Table 3.

It can be seen from the table that after each impact, the damage degree of the column specimens will increase and the ultrasonic wave velocity of the specimens will reduce after the damage. With each impact, the damage factor was changing; that is, after each impact, the degree of damage to the specimens was increasing. In order to more intuitively 
TABLE 1: Specimen design parameters.

\begin{tabular}{lccc}
\hline Specimen no. & Longitudinal reinforcement & Stirrup & Concrete strength grade \\
\hline R1 & $10 \$ 16$ & (8@50 & C40 \\
R2 & $10 \Phi 16$ & Ф8@50 & C40 \\
\hline
\end{tabular}

$\mathrm{S}$ represents the stainless steel reinforcement.

TABLE 2: Steel reinforcement material performance.

\begin{tabular}{lcccc}
\hline Reinforcement category & Yield strength $(\mathrm{MPa})$ & Tensile strength $(\mathrm{MPa})$ & Elongation (\%) & Elastic modulus (MPa) \\
\hline Reinforcement HRB335 & 368 & 552 & 16 & $2.0 \times 10^{5}$ \\
Stainless steel reinforcement S2304 & 748 & 866 & 17 & $1.93 \times 10^{5}$ \\
\hline
\end{tabular}
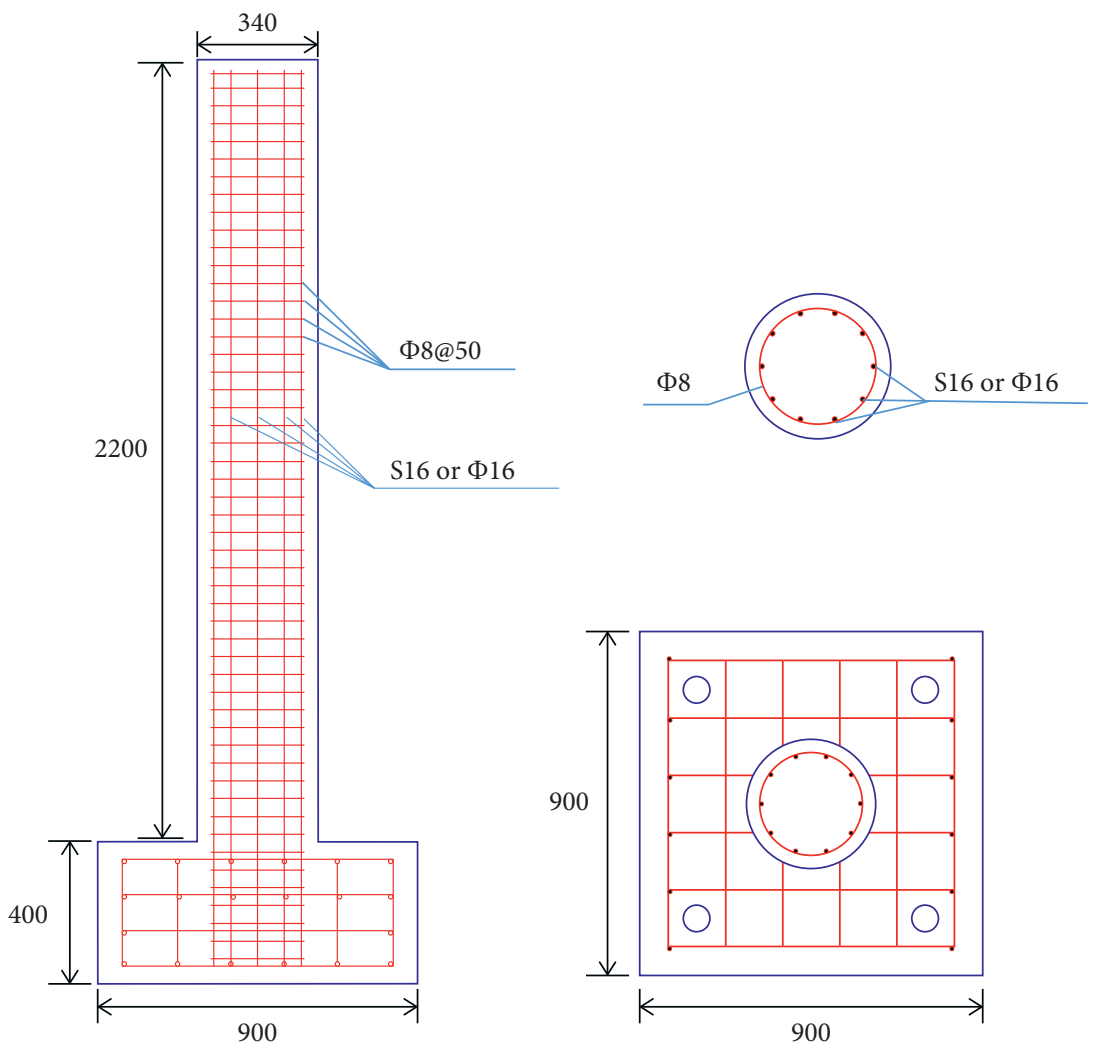

Figure 1: Detail drawing of reinforced concrete (unit: $\mathrm{mm}$ ).

obtain the relationship between the damage degree of the specimens and the damage factor $D$ after each impact, the relationship between the damage factor and the impact after the cumulative damage condition is shown in Figure 6.

It can be seen from Figure 6 that the specimens were regarded as nondamaged before impact. After each impact, the damage factor was increased. Under the same impact condition, the damage factor of the stainless steel-reinforced concrete specimen was smaller than the ordinary reinforced concrete specimen, indicating that the damage degree of the stainless steel-reinforced concrete specimen under the same impact condition was lower than that of the ordinary reinforced concrete specimen.

3.3. Crack Description and Analysis. Each of the specimen's crack initially developed from the bottom of the positively impacted specimen. With the increase in the impact energy, the crack propagated from the bottom of the positive impact to the center. Meanwhile, the crack correspondingly occurred to the impact back and point. As the impact energy continued to increase, the original crack at the midlower section of the front continued to develop toward the center. At the same time, the crack located on the reverse side continued to develop upwards. When the impact energy reached a certain level, a larger crack occurred at the bottom of the impact front, and the concrete on the impact back began to partially crush. The crack development areas were quite consistent with the main force areas of the specimens. The following table shows the width development of a major crack at the lower section of the impact front for each of the specimens with the changes in the drop hammer's height.

It can be seen from the aforementioned Table 4 that with the increase in the impact energy the width of this major 


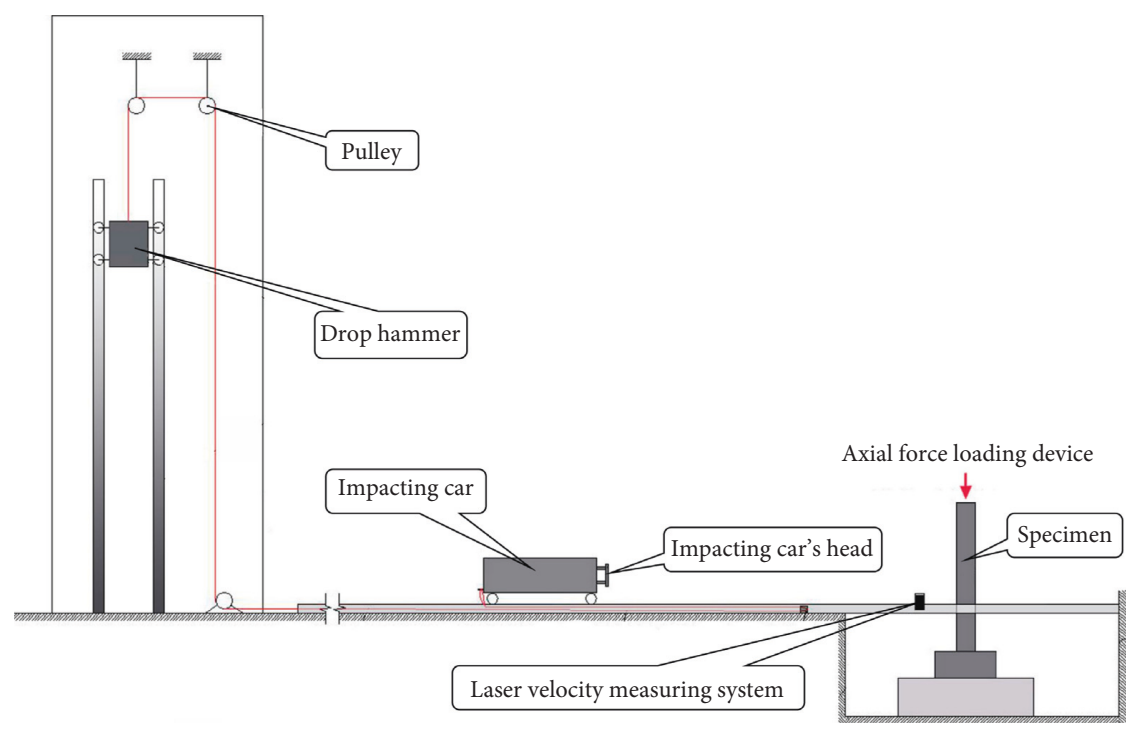

FIgURE 2: Ultrahigh drop hammer impact test system diagram.

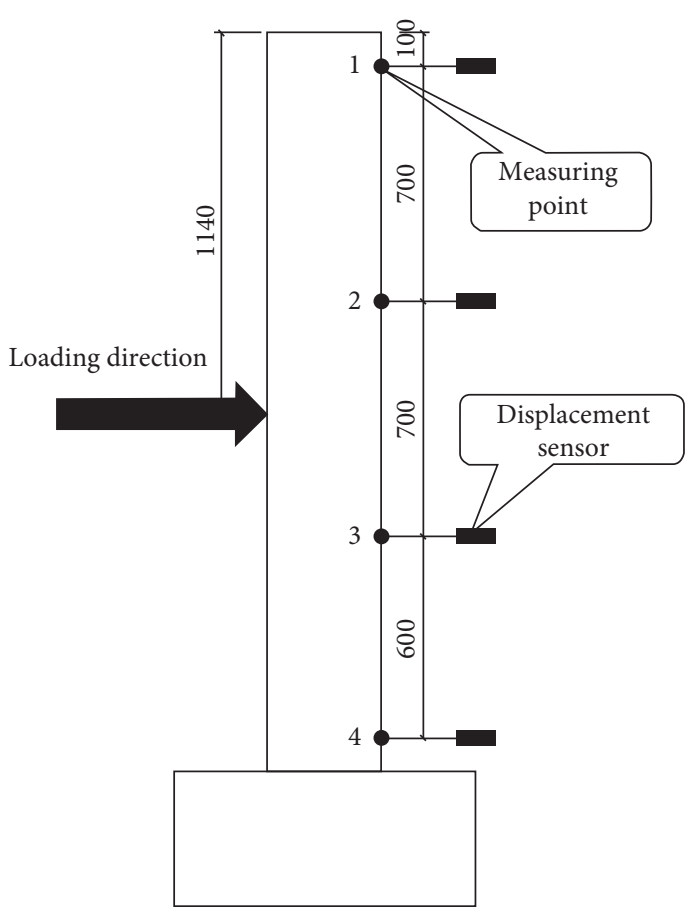

(a)

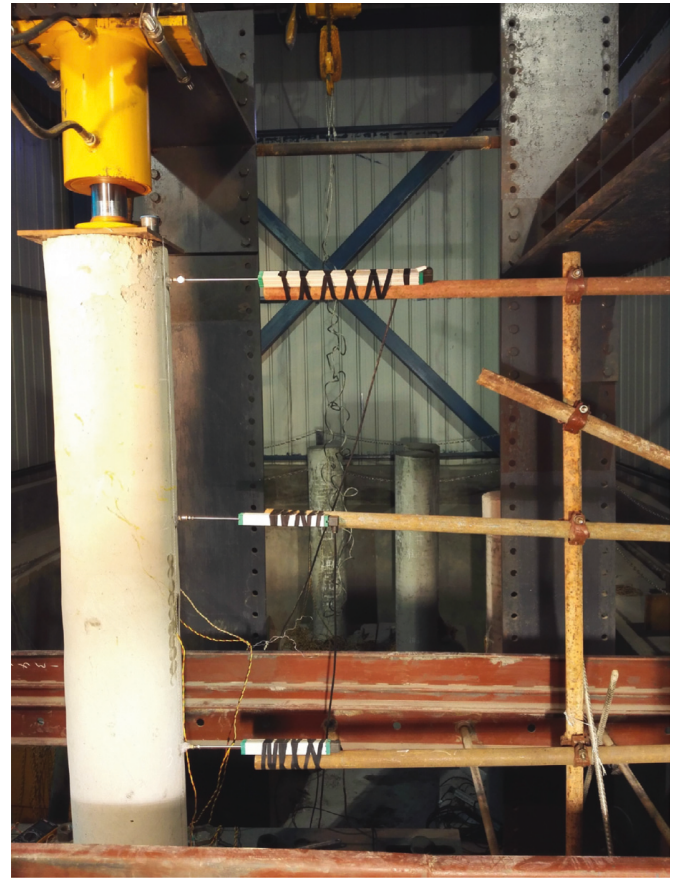

(b)

FIGURE 3: Arrangement diagram for displacement of specimen (unit: mm).

crack also increased. However, under the same impact condition, the development width of this major crack of the stainless steel-reinforced concrete specimen was lower than the crack width of the ordinary reinforced concrete specimen.

3.4. Displacement Time-History Curve. Figures 7 and 8 show the time-history curves of the four measuring points of the drop hammer when it was lifted to $8 \mathrm{~m}$. The displacements of the four measuring points were synchronously changed. The four displacement values of the R1 specimen were $17.3 \mathrm{~mm}, 11.3 \mathrm{~mm}, 4.9 \mathrm{~mm}$, and $1.2 \mathrm{~mm}$, respectively, and the four displacement values of the R2 specimen were $19.1 \mathrm{~mm}, 12.4 \mathrm{~mm}, 5.2 \mathrm{~mm}$, and $1.7 \mathrm{~mm}$, respectively. As it can be seen from the aforementioned data, the displacements of stainless steel-reinforced concrete specimen are lower than those of the ordinary reinforced concrete specimen under the same condition. 

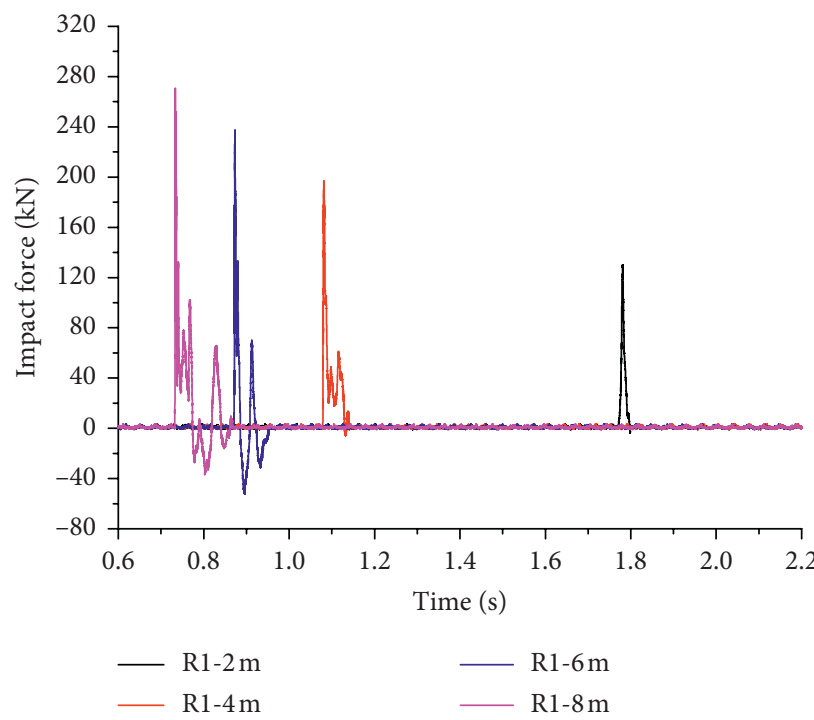

Figure 4: Impact force history of the R1.

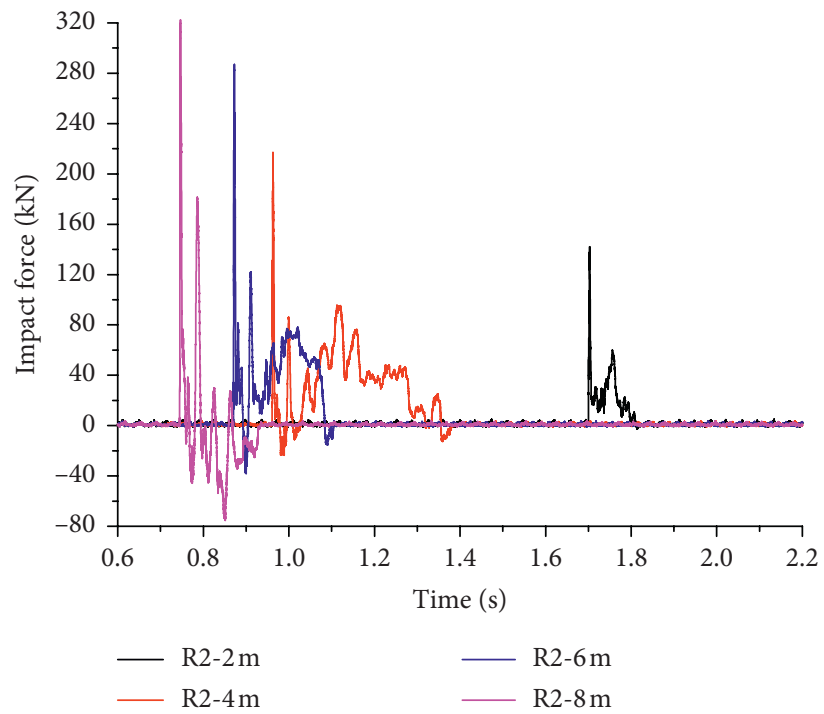

FIgURE 5: Impact force history of the R2.

TABle 3: Damage factor changes under continuous impact.

\begin{tabular}{|c|c|c|c|c|c|}
\hline \multirow{2}{*}{ Specimen } & \multirow{2}{*}{ Numbers of impacts } & \multicolumn{2}{|c|}{ Acoustic velocity average $(\mathrm{km} / \mathrm{s})$} & \multirow{2}{*}{ Damage factor } & \multirow{2}{*}{ Impact height } \\
\hline & & Before impact & After impact & & \\
\hline \multirow{4}{*}{$\mathrm{R} 1$} & 1 & 4.167 & 4.156 & 0.0053 & $2 \mathrm{~m}$ \\
\hline & 2 & 4.156 & 4.127 & 0.0139 & $4 \mathrm{~m}$ \\
\hline & 3 & 4.127 & 4.051 & 0.0365 & $6 \mathrm{~m}$ \\
\hline & 4 & 4.051 & 4.018 & 0.0162 & $8 \mathrm{~m}$ \\
\hline \multirow{4}{*}{$\mathrm{R} 2$} & 1 & 4.258 & 4.243 & 0.0070 & $2 \mathrm{~m}$ \\
\hline & 2 & 4.243 & 4.202 & 0.0192 & $4 \mathrm{~m}$ \\
\hline & 3 & 4.202 & 4.065 & 0.0641 & $6 \mathrm{~m}$ \\
\hline & 4 & 4.065 & 4.024 & 0.0201 & $8 \mathrm{~m}$ \\
\hline
\end{tabular}

3.5. Stress Nephogram. The finite element model of the specimen being impacted was established by using LSDYNA. Figures 9 and 10 show the numerical simulation stress diagrams of the two specimens under the impact energy of the drop hammer to $8 \mathrm{~m}$. The figures show the impact of the impact body on the left side of the specimen. 


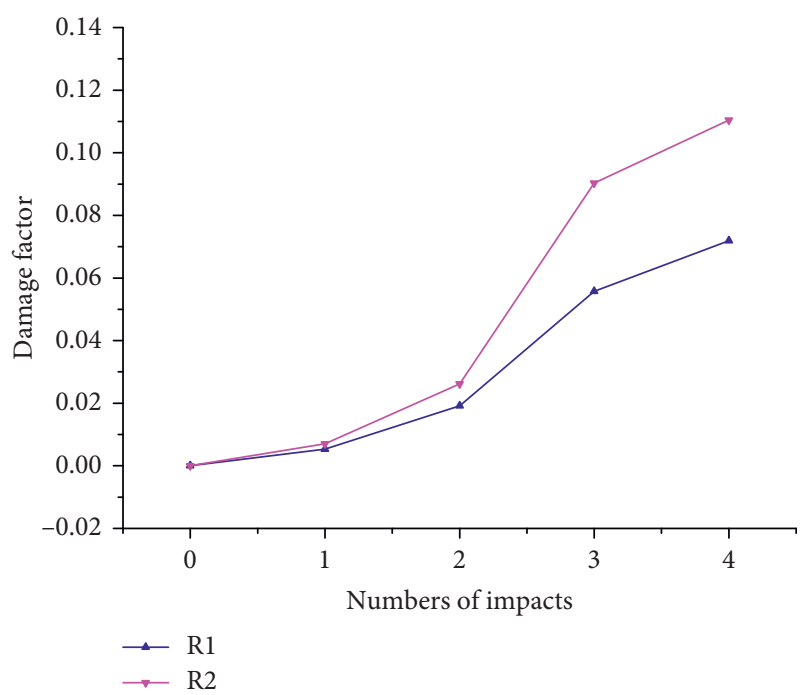

Figure 6: Damage factor change curve after each impact.

TABle 4: Crack development under different impact energies.

\begin{tabular}{lcccc}
\hline \multirow{2}{*}{ Specimen } & \multicolumn{3}{c}{ Crack widths at each drop hammer height $(\mathrm{mm})$} \\
& $2 \mathrm{~m}$ & $4 \mathrm{~m}$ & $6 \mathrm{~m}$ & $8 \mathrm{~m}$ \\
\hline R1 & 0 & 0.230 & 0.294 & 0.318 \\
R2 & 0 & 0.298 & 0.422 & 0.554 \\
\hline
\end{tabular}

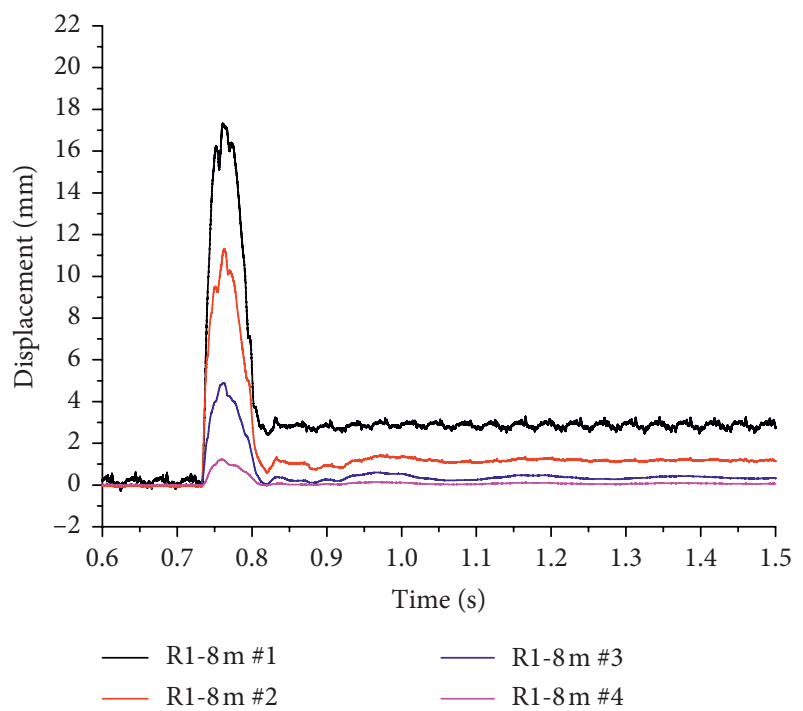

Figure 7: Displacement history of R1-8 m.

It can be seen from the stress diagram that before the impact, since the vertical load has been applied on the top of the specimens, the stress value at the top of the specimen was large. When the impact body has just come into contact with the specimens, the stress is greater near the position of the impact point and at the bottom of the reverse side. As the impact continues, the stressed part gradually increases mainly at the bottom of the back, and then the area of the back bottom and the area of the impact point develop toward both sides. From the whole impact process, the

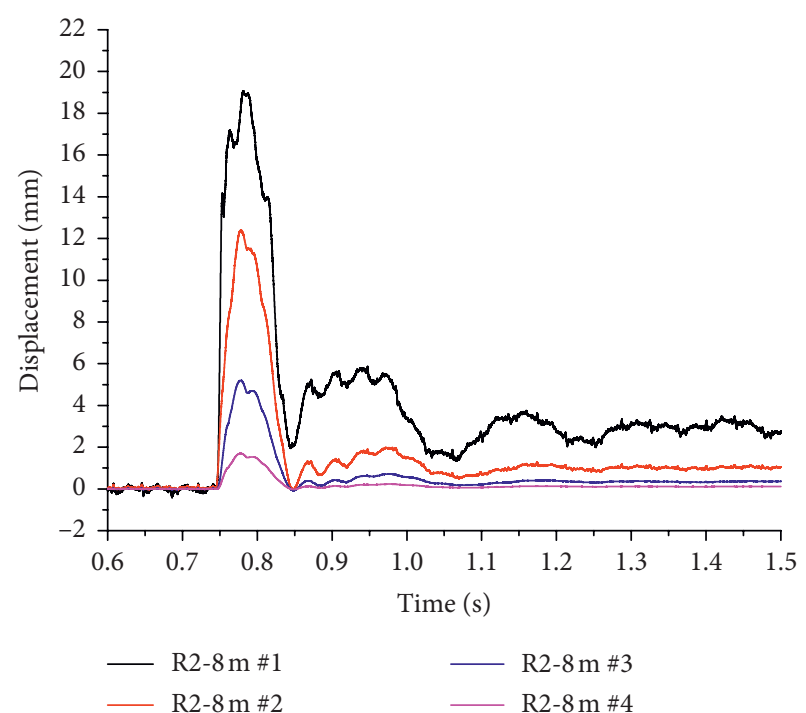

Figure 8: Displacement history of R2-8 m.

main stress change areas of the two specimens were concentrated near the bottom of the impact back and the impact point, and the stress changes at the same position were about the same. When the specimen impacted the bottom stress to the maximum, the specimen displacement also reached the maximum. However, it can be seen from the figure that at the same time, the maximum stress of the stainless steel-reinforced concrete specimen was smaller than that of the ordinary reinforced concrete specimen. 


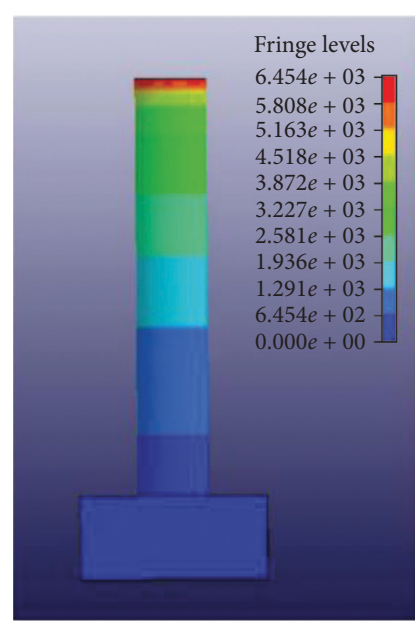

(a)

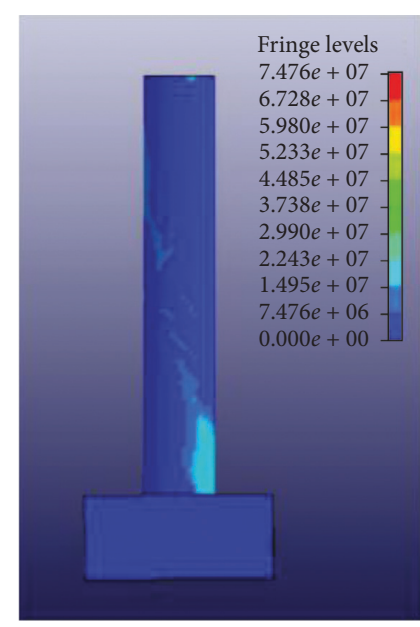

(b)

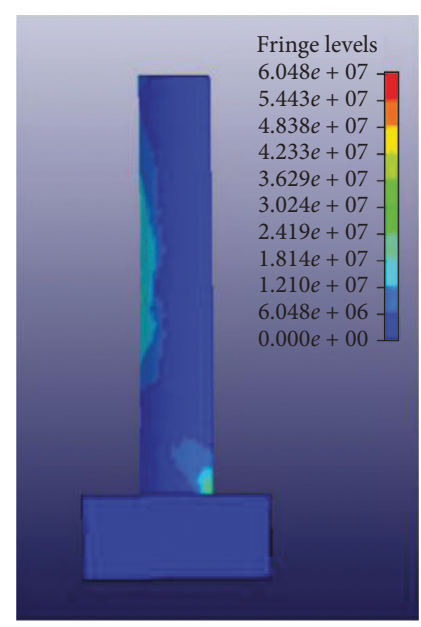

(c)

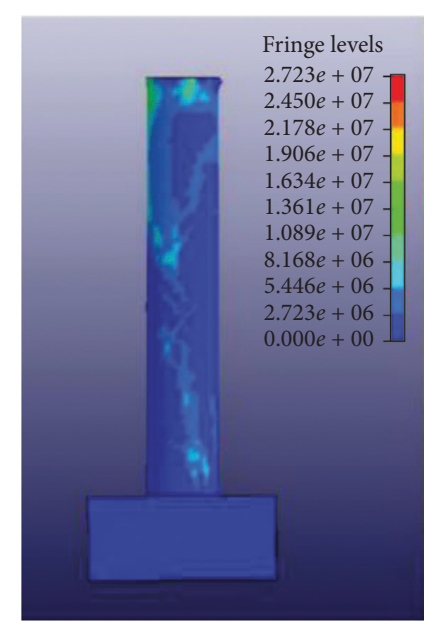

(d)

Figure 9: Stress nephogram of R1-8 m (Unit: Pa): (a) R1-8 m (T=0.030 s), (b) R1-8 m (T=0.035 s), (c) R1-8 m (T=0.062 s), and (d) R1-8 m $(T=0.089 \mathrm{~s})$.

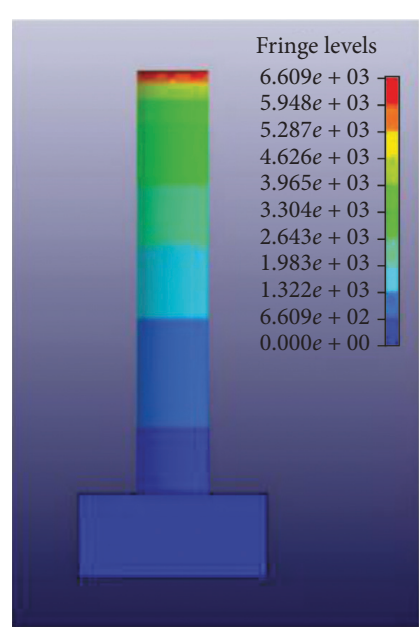

(a)

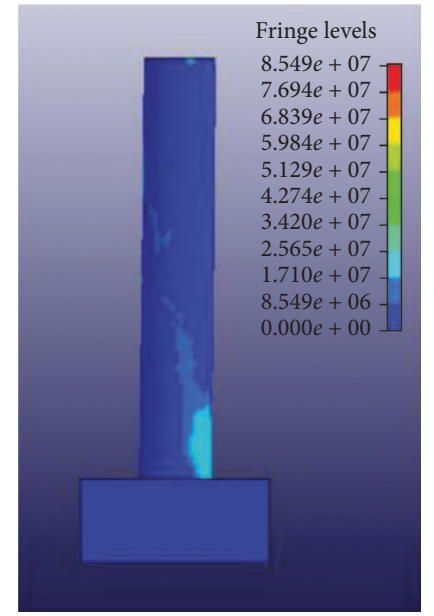

(b)

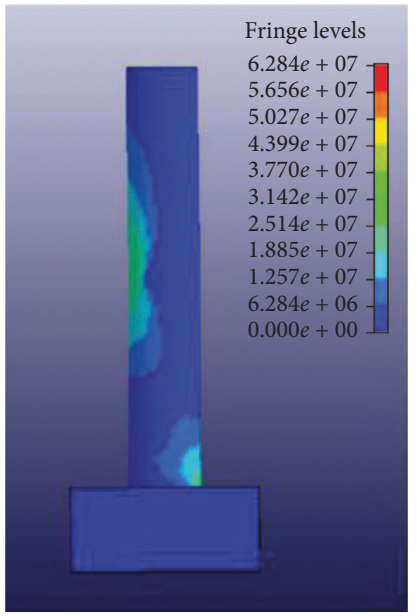

(c)

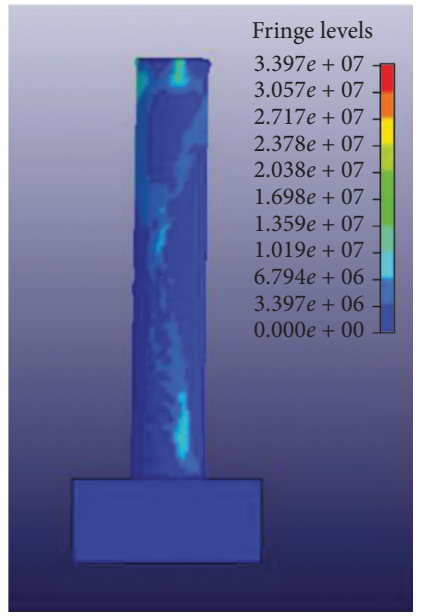

(d)

Figure 10: Stress nephogram of R2-8 m (Unit: Pa): (a) R2-8 m ( $T=0.030 \mathrm{~s}$ ), (b) R2-8 m ( $T=0.035 \mathrm{~s})$, (c) R2-8 $\mathrm{m}$ ( $T=0.062 \mathrm{~s}$ ), and (d) R2-8 m $(T=0.089 \mathrm{~s})$.

\section{Conclusions}

In this paper, multiple horizontal impact tests were carried out on the stainless steel-reinforced concrete column specimen and the ordinary reinforced concrete column specimen with the same longitudinal reinforcement diameter and established the finite element model. The following conclusions were obtained by analyzing the impact time history, displacement time history, concrete damage variation, and crack recording results of reinforced concrete column specimens under step impact loading.

(1) With the increase of impact energy, the impact peak gradually increased. By comparing with the ordinary reinforced concrete specimen, the maximum impact force and displacement peak of the stainless steelreinforced concrete specimen are smaller under the same impact conditions.
(2) Based on the ultrasonic wave velocity and introducing the damage factor, the damage degree of the specimen was quantitatively described and compared with the ordinary reinforced concrete specimen with the same longitudinal reinforcement diameter, the damage degree of the stainless steelreinforced concrete specimen was lower.

(3) The crack of the specimens start from the bottom area of the front surface of the impact. As the impact energy increases, it gradually extended toward the middle direction. At the same time, the crack occurred at the opposite side of the impact surface and the impact point and gradually developed toward the upper and middle parts of the back surface. When the impact energy reached a certain level, a large crack appeared at the bottom of the impact front, and the concrete at the bottom of the impact was crushed, 
which was consistent with the finite element simulation results.

\section{Data Availability}

The data sets used and analyzed during the current study are available from the corresponding author on reasonable request.

\section{Conflicts of Interest}

The authors declare that they have no conflicts of interest.

\section{Acknowledgments}

The authors would like to express their appreciation to the financial support from the National Natural Science Foundation of China (nos. 51678164 and 51478118), the Guangxi Natural Science Foundation Program (2018GXNSFDA138009), the Guangxi Science and Technology Plan Projects (AD18126011), the Scientific Research Foundation of Guangxi University (XTZ160590), the Guangxi Special Funds for Special Experts granted to Dr. Bo Wu, and the Major Project (Natural Science) of the Department of Education of Guangdong Province (2014KZDXM064).

\section{References}

[1] L. Tian and C. Zhu, "Damage evaluation and protection technique of RC columns under impulsive load," Engineering Mechanics, vol. 30, no. 9, pp. 144-150, 2013.

[2] X. W. Cheng, Y. Li, X. Z. Lu et al., "Numerical investigation on dynamic response of reinforced concrete columns subjected to impact loading," Engineering Mechanics, vol. 32, no. 2, pp. 53-63, 2015.

[3] M. J. Loedolff, The Behaviour of Reinforced Concrete Cantilever Columns under Lateral Impact Load, Stellenbosch University, Stellenbosch, South Africa, 1989.

[4] F. Liu, Q. Z. Luo, B. Yan et al., "Numerical study on the failure mode of RC column subjected to lateral impact," Journal of Vibration and Shock, vol. 36, no. 16, pp. 122-127, 2017.

[5] C. Demartino, J. G. Wu, and Y. Xiao, "Response of sheardeficient reinforced circular RC columns under lateral impact loading," International Journal of Impact Engineering, vol. 109, pp. 196-213, 2017.

[6] J. Cai, J.-B. Ye, Q.-J. Chen, X. Liu, and Y.-Q. Wang, "Dynamic behaviour of axially-loaded RC columns under horizontal impact loading," Engineering Structures, vol. 168, pp. 684-697, 2018.

[7] X. Y. Zhou, R. J. Ma, and A. R. Chen, "Anti-shear reliability analysis for a reinforced concrete column subjected to rockfall impact," Journal of Vibration and Shock, vol. 36, no. 7, pp. 262-270, 2017.

[8] X. Wang, Y. Zhang, Y. Su, and Y. Feng, "Experimental investigation on the effect of reinforcement ratio to capacity of RC column to resist lateral impact loading," Systems Engineering Procedia, vol. 1, pp. 35-41, 2011.

[9] W. C. Zhao and J. Qian, "Performance of reinforced concrete pier columns subjected to lateral impact," Chinese Journal of Engineering, vol. 3, pp. 1-11, 2019.

[10] G. X. Zhang, Z. Q. Chen, J. Lu, S. Xu, and X. Zhou, "Experimental study on the impact properties of concrete bridge pier reinforced with stainless steel rebar," Journal of Testing and Evaluation, vol. 46, no. 4, pp. 1650-1658, 2018.

[11] G. X. Zhang, S. X. Xu, H. B. Xie et al., "Behavior of stainless steel-reinforced concrete piers under lateral impact loading," Advances in Mechanical Engineering, vol. 9, no. 5, pp. 1-8, 2017.

[12] G. X. Zhang and S. X. Xu, "Test study on the impact damage performance of stainless steel reinforced concrete," in AIP Conference Proceedings, vol. 1829, Article ID 020029, AIP Publishing, Hangzhou, China, April 2017. 


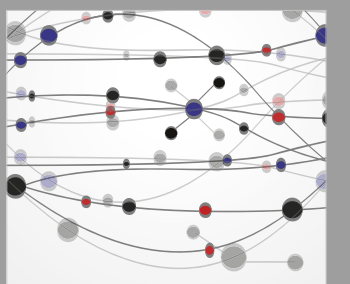

The Scientific World Journal
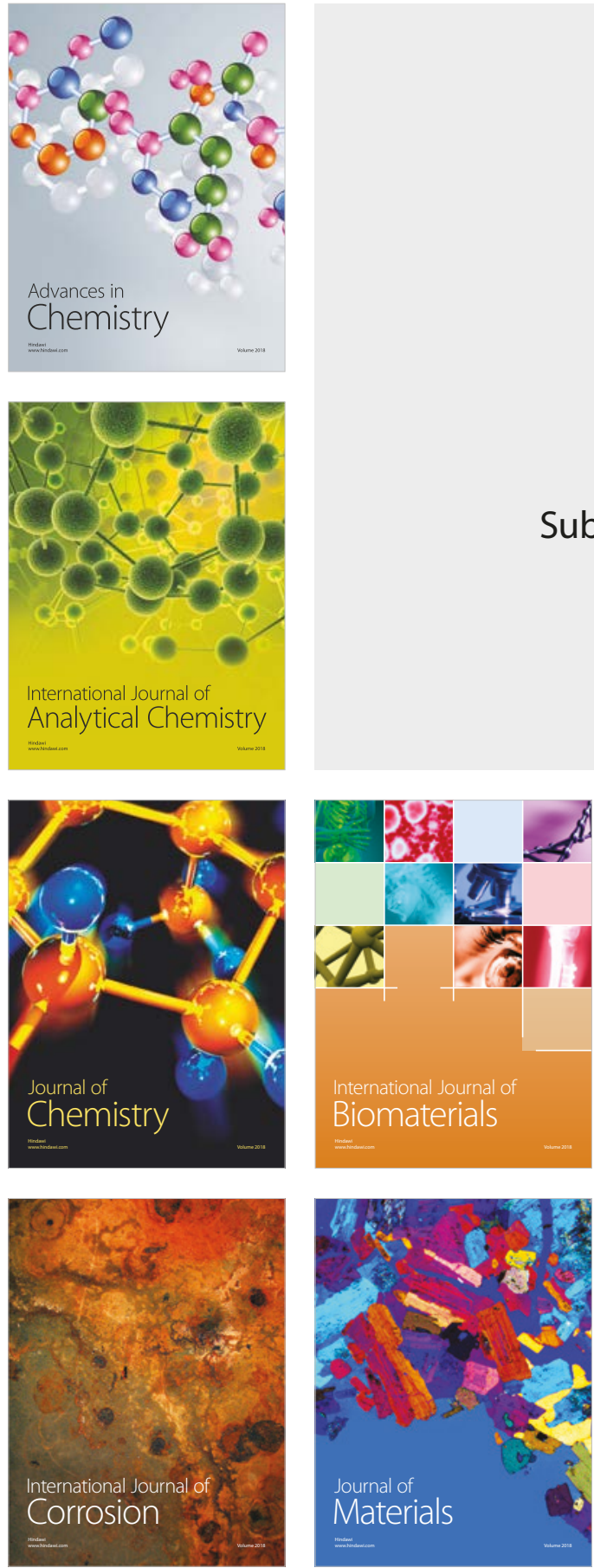

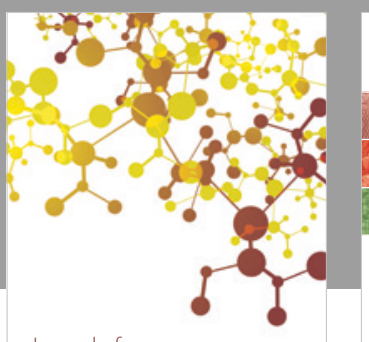

Journal of

Applied Chemistry
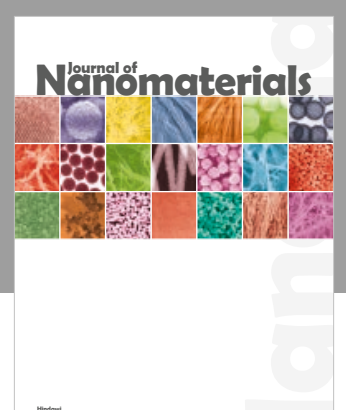

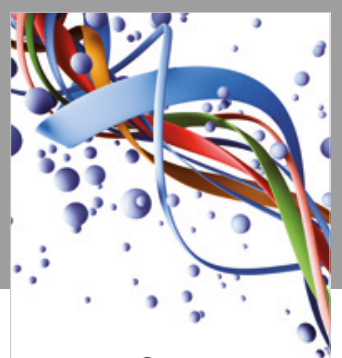

Scientifica

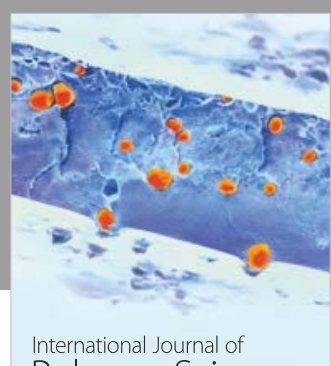

Polymer Science

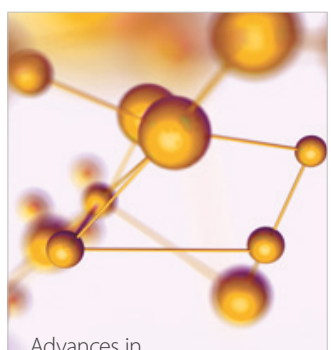

Physical Chemistry
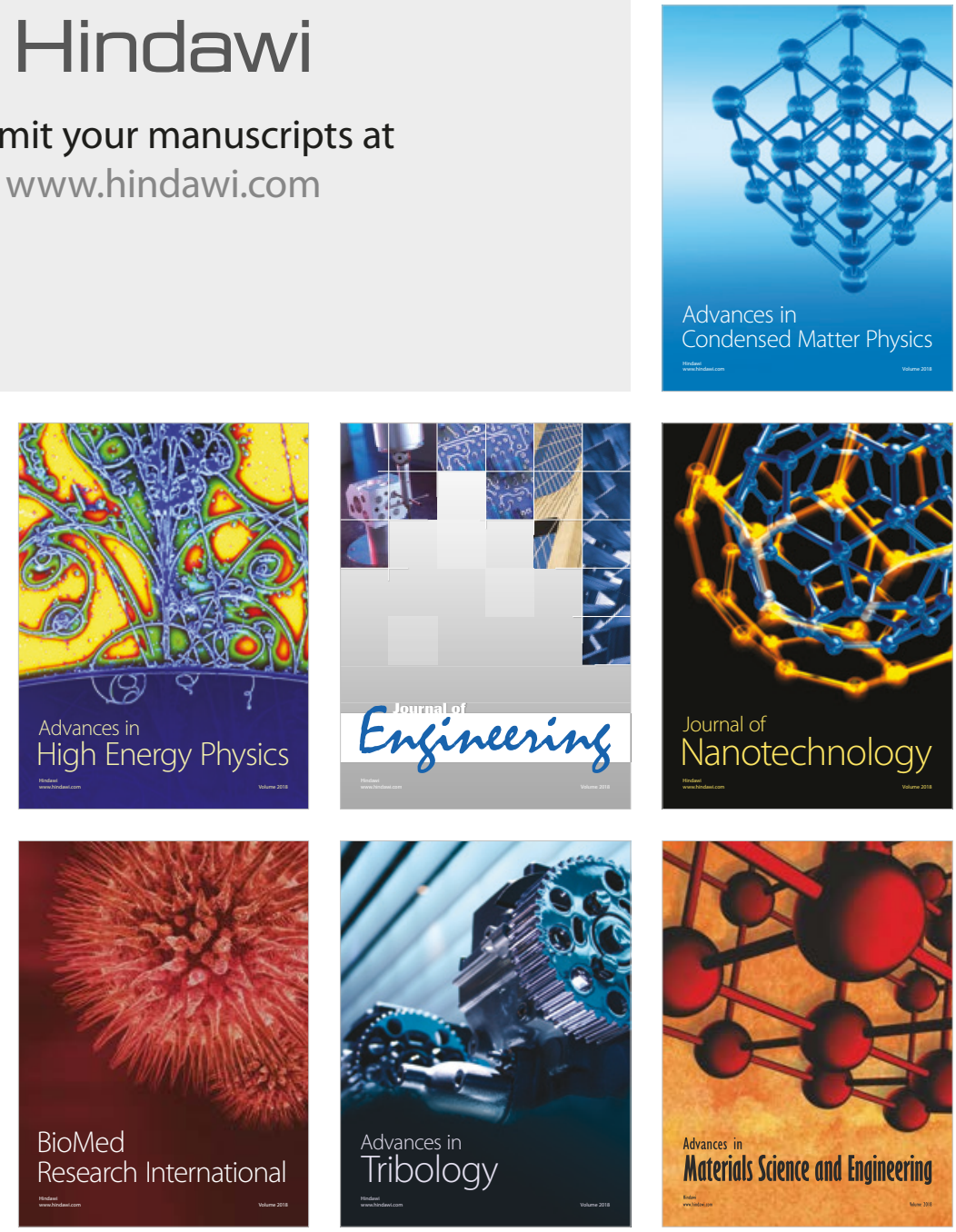